\title{
Factors Influencing the Behavior Intention of Mobile Commerce Service Users: An Exploratory Study in Hong Kong
}

\author{
Ken Kin-Kiu Fong ${ }^{1}$ \& Stanley Kam Sing Wong ${ }^{2}$ \\ ${ }^{1}$ University of South Australia, Australia \\ ${ }^{1}$ Wireless Technology Industry Association (WTIA), Hong Kong \\ ${ }^{2}$ University of Newcastle, Australia \\ Correspondence: Ken Kin-Kiu Fong, University of South Australia, Australia. E-mail: ken@fong.com.hk
}

Received: April 13, 2015

Accepted: April 28, 2015

Online Published: June 20, 2015

doi:10.5539/ijbm.v10n7p39

URL: http://dx.doi.org/10.5539/ijbm.v10n7p39

\begin{abstract}
This study identifies and explores key determinants of the behavior intention of mobile commerce service users in Hong Kong. Findings from 390 respondents to a questionnaire survey indicated that the four key factors influencing users' intention to use a mobile commerce service are: the attitude of users toward the mobile commerce service, the users' perceived subjective norm, or the intensity of social and peer group pressure to use a mobile commerce service; the perceived ease of use of the mobile commerce service, and the localization of the mobile commerce service. This study contributes to the body of knowledge in the fields of service marketing, technology adoption, and customer relationship management.
\end{abstract}

Keywords: technology adoption, intention to use, service marketing, mobile commerce, attitude, subjective norm

\section{Introduction}

In the information age, a mobile phone is not only a personal communication device but also a computing platform linking people to various kinds of services (Dholakia \& Dholakia, 2004). Such changes became more obvious after the launch of $3 \mathrm{G}$ and $4 \mathrm{G}$ technology. The changes from $2 \mathrm{G}$ to $3 \mathrm{G}$ in 2004 and from $3 \mathrm{G}$ to $4 \mathrm{G}$ in 2009 triggered a remarkable growth in number of smartphone users in Hong Kong.

Simply installing a mobile app to a smartphone allows users access to mobile commerce services, such as mobile banking, mobile investing, mobile auctions, and mobile shopping. It is estimated that shopping by mobile phone worldwide will grow to US\$119 billion in 2015, representing approximately $8 \%$ of the total e-commerce market (Arpaci, Yardimci, Özkan, \& Türetken, 2012).

Despite the initial high expectation of substantial growth, the market has taken much longer than expected to accept mobile commerce (Khalifa \& Shen, 2008). The creation of a successful and widely adopted mobile commerce environment continues to be difficult to achieve (Herndon, 2013). However, the recent explosive increase in ownership of smartphones has shown the potential for a boom in mobile commerce (Tsai \& Ho, 2013). It has therefore become important to understand the key factors affecting the successful adoption of mobile commerce by users.

Previous studies on mobile commerce, especially those based on the technology acceptance model (TAM) developed by Davis, Bagozzi and Warshaw (1989), mostly focused on finding the collective contribution of independent variables, such as compatibility, perceived usefulness, and perceived ease of use, on the dependent variable of actual use via the mediating variables of attitude and behavior intention. Less attention has been paid to the relative importance of each of the independent variables.

This study fills that research gap by combining the TAM with the theory of planned behavior (TPB), developed by Ajzen (1991), and by using multiple stepwise regression analysis to determine the relative importance of various factors that might affect the behavior intention of mobile commerce users. The factors used in this study are: attitude, subjective norm, ease of use, usefulness, compatibility, mobility, personalization, localization, gender, and marital status. Discovering the relative importance of the ten factors will help practitioners in the mobile commerce industry to concentrate their limited resources on the most productive areas. 


\section{Literature Review}

\subsection{Background of the Study}

At the beginning of the millennium there were only 500 million mobile subscriptions globally but that number had mushroomed to over 5.9 billion (an 87\% global penetration), by the end of 2011 (ITU, 2011). In Hong Kong, the mobile penetration rate exceeded $200 \%$ in the year 2011 (OFTA, 2012). Over the last decade, the adoption and diffusion of mobile phones has been exceptionally rapid in many parts of the world. The mobile phone empowers individuals in several ways and many people consider their mobile phone to be an extension of their persona. With the advent of wireless and mobile technology, people using a smartphone can not only can talk and see each other anywhere and anytime, but can also make banking transactions, do shopping, watch TV, play games, and chat with friends.

After the spread of high-speed 3G mobile networks and launching of the more advanced $4 \mathrm{G}$ networks, mobile Internet (or wireless Internet) is the next technological advance that is ushering in dramatic changes in the world ( $\mathrm{Lu}$ and $\mathrm{Su}, 2003$ ). Mobile Internet is wireless access to digitalized information available on the Internet through mobile devices that constitutes convergence of the Internet, wireless and mobile technologies, providing a powerful and convenient way of accessing the Internet anytime and anywhere ( $\mathrm{Lu} \mathrm{\&} \mathrm{Su}, 2003$; Cherian \& Rudrapatna, 2013).

The business world is witnessing profound changes under the influence of mobile and wireless technology and the opportunity for mobile commerce has opened up. Yankee Group (2010) estimated that the worldwide mobile commerce market is expected to exceed USD 1 trillion by 2015. A number of mobile commerce applications have been developed and are already in use, covering a wide range of business functions from advertising and auctions to banking and shopping, besides many other value-added phone services (Wu \& Wang, 2006; GS1, 2008). Among these innovative usages, shopping via the Internet is considered as having great potential due to its unique characteristic of allowing consumers to shop online anytime and anywhere (Dholakia \& Dholakia, 2004; $\mathrm{Lu} \& \mathrm{Su}, 2003$ ). Mobile shopping worldwide will grow to US\$119 billion in 2015 (Arpaci et al., 2012), representing about $8 \%$ of the total e-commerce market.

It's not difficult to see mobile commerce as the next major shopping platform, but low consumer adoption remains a hurdle (Tsai, 2009). Although Hong Kong has a mobile phone penetration rate of over $200 \%$, use of mobile commerce technology is not that significant. The issue of building a successful and widely adopted mobile commerce environment remains ambiguous. However, the explosive growth of smartphones driven by iPhone and Android operating systems may change the situation. Although mobile online shopping purchases have been mainly driven by music and entertainment apps, there is great potential for a boom in mobile commerce (Tsai, 2009). To take advantage of this opportunity, it is necessary to understand the nature of mobile commerce as well as the key factors that affect its adoption.

Shopping is a complicated behavior involving rational decision-making and social interaction by the consumer (Wu \& Wang, 2006). There are similarities and differences among physical shopping, online shopping through a web browser on a personal computer, and mobile commerce using a micro-browser or an application on a mobile device (Wu \& Wang, 2006). It is important for retail brands to commit to a mobile strategy for connecting their mobile commerce consumers through research, comparison and purchase. There is little doubt that mobile commerce is expanding on the back of the success of electronic commerce and is expected to have a much wider coverage as it offers a more personalized and interactive way of communication.

At the same time, leading global retailers have started thinking of creating a more interactive retail experience by reaching out to consumers with mobile services and applications that make them more productive in the store, and are engaging them in unique ways that transform the shopping experience (Dunne et al., 2008). In order to stay competitive in this market, retailers in Hong Kong should also consider mobile commerce strategies.

\subsection{Behavior Intention}

Behavior intention is defined as consumer readiness and likelihood to use mobile commerce services (Peña \& Brody, 2014; Ajzen, 1991). In this study, behavior intention is the only dependent variable. Prior studies identified many factors that might affect behavior intention. Ajzen and Fishbein (1980) in their theory of reasoned action (TRA) suggested that both attitude and subjective norms are capable of affecting human behavior intention. According to the TRA, attitude consists of attitudinal beliefs about the consequences of performing the behavior weighted by one's valuation of the consequences (Ajzen \& Fishbein, 1980; Fishbein \& Ajzen, 1975). Meanwhile subjective norm is defined as "the person's perception that most people who are important to him or her think he should or should not perform the behavior in question" (Fishbein \& Ajzen, 1975, 
p. 302).

Therefore, the first two hypotheses of this study are:

H1: Hong Kong mobile phone users' attitude toward mobile commerce affects their intention to use mobile commerce services.

H2: Hong Kong mobile phone users' subjective norm toward mobile commerce affects their intention to use mobile commerce services.

The technology acceptance model (TAM) identified the fundamental variables that determine computer acceptance (Davis, Bagozzi, \& Warshaw, 1989). According to the TAM, a user's behavior intention toward the use of a computer system can be predicted by the user's attitude toward that system, perceived usefulness and perceived ease of use of the system.

Perceived ease of use has been defined by Davis $(1989$, p. 320) as "the degree to which a person believes that using a particular system would be free of effort", while perceived usefulness has been defined as "the degree to which a person believes that using a particular system would enhance his or her job performance" (Davis, 1989, p. 320). Prior studies on consumer behavior found that a consumer's perceived ease of use and perceived usefulness of a system affect behavior intention of the consumer toward the system (Gao \& Bai, 2014; Li, 2013).

Therefore, the third and forth hypotheses of this study are:

H3: Hong Kong mobile phone users' perceived ease of use of mobile commerce affects their intention to use mobile commerce services.

H4: Hong Kong mobile phone users' perceived usefulness of mobile commerce affects their intention to use mobile commerce services.

Besides the commonly studied independent variables, which might affect a consumer's intention to use mobile commerce services, compatibility, mobility, personalization and localization are also identified as a possible factors that influence consumer's intention to use mobile commerce services.

Compatibility is defined as the degree to which using mobile commerce services is perceived as being consistent with the user's existing lifestyle, values, needs and preferences (Chen, Gillenson, \& Sherrell, 2002; Langley, Bijmolt, Ortt, \& Pals, 2012). Chen, Gillenson and Sherrell (2002) found that compatibility has a positive influence on consumer behavior in online shopping. It is hypothesized that the same causal link also exists in the mobile commerce service setting in Hong Kong. Therefore, the fifth hypothesis is:

H5: Hong Kong mobile phone users' perceived compatibility of mobile commerce affects their intention to use mobile commerce services.

The major different between mobile commerce and shopping from a physical shop is the mobility. Mobility is defined as the degree to which a system can instantly access the Internet, making the required information immediately available and services ready to use (Chiang \& Liao, 2012; Ko, Kim, \& Lee, 2009). Therefore the sixth hypothesis is:

H6: Mobility of the system affects Hong Kong mobile phone users intention to use mobile commerce services.

Prior studies have found that personalized services and products tailored to meet individual consumer's requirements could increase consumers' purchasing intention (Tong, Wong, \& Lui, 2012). Similar findings on the effect of personalized services were also reported in the mobile shopping setting (Ko, Kim, \& Lee, 2009; Park, 2014). By using data mining, it is possible for a service provider to provide timely, accurate and personalized services to its customers (Pan, 2014; Tong et al., 2012). As most smartphones are equipped with the Global Positioning System (GPS) and general packet radio service (GPRS), it is also possible for the service provider to deliver location specific information, such as shop discount and special offers, and location specific services to its customers (Cherian \& Rudrapatna, 2013). Therefore, the seventh and eighth hypotheses are:

H7: The ability of Hong Kong mobile commerce service providers to personalize their service affects their users' intention to use mobile commerce services.

H8: The ability of Hong Kong mobile commerce service providers to localize their service affects their users' intention to use mobile commerce services.

Prior research indicates that demographic factors such as gender and marital status might affect the readiness to accept new technology and the perception of consumer products (Zhang, Nyheim, \& Mattila, 2014). Therefore, the ninth and tenth hypotheses are: 
H9: The gender of Hong Kong mobile phone users is associated with their intention to use mobile commerce services.

H10: The marital status of Hong Kong mobile phone users is associated with their intention to use mobile commerce services.

\section{Research Model}

The research model in Figure 1 below illustrates the factors that have been hypothesized as affecting users' intention to use mobile commerce services.

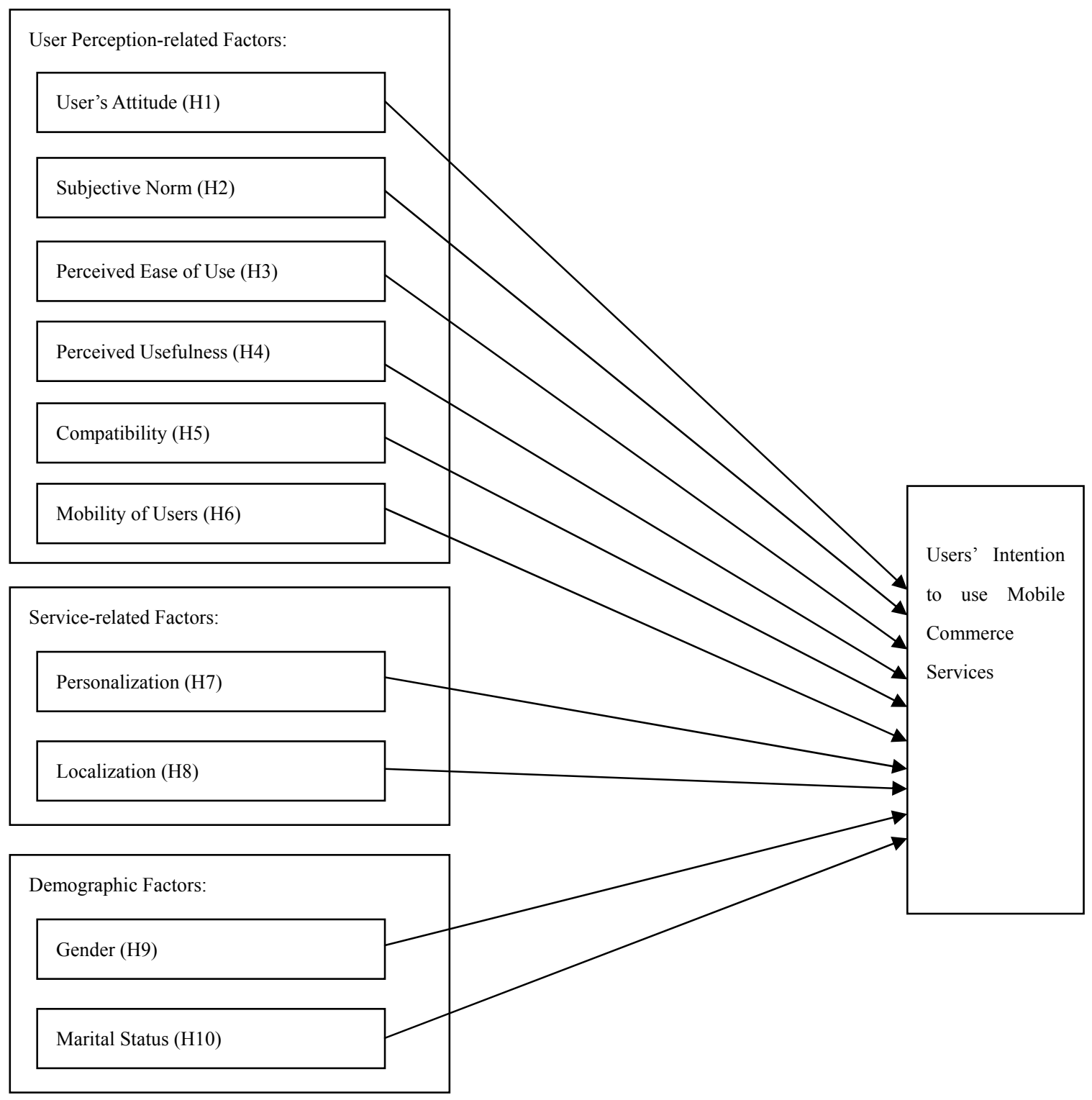

Figure 1. Research model

\section{Research Design and Methodology}

A quantitative research approach was adopted using an online questionnaire survey with a 7-point Likert scale to measure the study's dependent variable and independent variables. The respondents' demographic data were also collected to examine whether gender, age, marital status, and educational level influence behavior intention to use mobile commerce services. A total of 1,200 email invitations were sent to potential respondents, which were randomly selected from the database of a local executive development centre in Hong Kong. 


\subsection{Data Collection and Measurement Instrument}

Before administering the questionnaire it was pre-tested and pilot tested. In the pretest, each question was evaluated for explicitness, ease of understanding and appropriateness. Ten expert users of online and mobile commerce were invited as pre-testers to complete the questionnaire and provide comments. Based on their feedback, slight modifications were made to improve readability and ensure accuracy and appropriateness. For the pilot test, the post-test interviews with the thirty participants who completed the pilot test indicated that the questionnaire was properly designed and there were no misunderstandings or ambiguities in it. Subsequently, 1,200 email invitations were sent out for the full survey, which elicited 390 responses and provided a $32.5 \%$ response rate.

The measurement instrument used questions from previous research. The questions used to measure the 'intention' dependent variable were adapted from Lu and Su (2009) and Chen et al. (2002), while the questions adopted for measuring the independent variables were as follows: 'usefulness' and 'ease of use' from Yu et al. (2005) and Davis (1989); 'compatibility' from Chen et al. (2002) and Vijayasarathy (2004); 'attitude' and 'subjective norm' from Yu et al. (2005); 'personalization' from Xu (2006); 'mobility' from Hong et al. (2008); and 'localization' from Chang et al. (2006).

\subsection{Selection of Statistical Technique}

There is an abundance of research on consumer behavior with the majority based on TAM or TPB focusing on the causal link between dependent variable and independent variables via the mediating variables. Little attention has been placed on finding the relative importance of various independent variables on the dependent variable of behavior intention. This study uses a stepwise regression model to examine the relative influence of different factors. The first variable selected by the model and entered into the regression equation is the most important factor influencing behavior intention of users of mobile commerce applications in Hong Kong; the second variable selected is the second most important; and so on. The stepwise regression procedure stops automatically when no more variables can produce a significant improvement in the model's explanation power.

\section{Data Analysis}

The collected data were statistically analyzed using descriptive analysis, reliability tests, correlations, and stepwise regression analysis.

\subsection{Demographic Characteristics of Survey Respondents}

There were 390 respondents to questionnaire survey with $210(53.8 \%)$ of them female and $180(46.2 \%)$ male. The majority of respondents are in the age range of 25-34 (186 out of 390 or 47.7\%) and 35-44 (116 out of 390 or $29.7 \%)$, and $165(42.3 \%)$ of the respondents are married. The majority of respondents are holders of a Bachelor's degree (202 out of 390 or 51.8\%), followed by those with an Associate degree (69 out 390 or 17.7\%) and those with a Master's degree or higher (51 out of 390 or 13.1\%).

\subsection{Reliability Tests}

As all measuring items were adapted from previous studies, no factor analysis was conducted in this study. However, in order to ensure the quality of the data prior to further analysis, common method bias using Harman one factor test and scale reliability using Cronbach's alpha coefficients were conducted. The Harman one factor test indicated that the most influential factor accounted for only $47.4 \%$ percent of the variance and the fact that no single factor accounted for more than $50 \%$ of the variance in the data indicated that common method bias is not an issue in this study. The Cronbach's alpha coefficient of all nine variables was in the range of 0.874 to 0.984 , indicating a good reliability of data collected.

\subsection{Control Variables}

Gender, marital status, education level, and age were used as control variables in this study. One-way analysis of variance (Anova) and the t-test were used to compare the mean values among various subgroups. The results showed that: the mean of behavior intention for male and female is 5.19 and 4.91 respectively $(\mathrm{p}>0.05)$, indicating that gender does not affect the behavior intention of consumers using mobile commerce services in Hong Kong (H9 rejected); the mean of behavior intention for single and married is 5.04 and 5.05 respectively ( $>0.05)$, indicating that marital status does not affect the behavior intention of consumers using mobile commerce services in Hong Kong (H10 rejected); the mean of behavior intention for respondents with high school, Associate degree, Bachelor's degree and Master's degree is 5.10, 4.93, 5.10 and 4.85 respectively, indicating that the education level of the respondents does not affect the behavior intention of consumers using mobile commerce services in Hong Kong; and the mean of behavior intention for respondents in the age range of 
18-24, 25-34, 35-44 and 45 or above is 5.13, 5.07, 4.95 and 5.06 respectively, indicating that age does not affect the behavior intention of consumers using mobile commerce services in Hong Kong. As there are no significant differences in the mean values of different subgroups in terms of gender, marital status, education level and age, all that data could be analyzed as a whole.

\subsection{Stepwise Regression}

The ANOVA of stepwise regression models shown as Table 1 reveals that there are four stepwise regression predictor models. Table 2 provides a summary of the stepwise regression analysis results, while Table 3 shows the coefficients of the stepwise regression models.

The 'attitude' variable was found to be a good fit for the first stepwise regression model (Adjusted $\mathrm{R}$ square = 0.476 and ANOVA results $\mathrm{F}=354.574, \mathrm{p}<0.001$ ) and with $47.6 \%$ of the variance it is significant in predicting behavior intention (H1 supported); the 'subjective norm' variable was found to be a good fit for the second stepwise regression model (Adjusted $\mathrm{R}$ square $=0.520$ and ANOVA results $\mathrm{F}=212.051, \mathrm{p}<0.001$ ) and with $52.0 \%$ of the variance, an increase of $4.4 \%$ over the first model, it is significant in predicting behavior intention ( $\mathrm{H} 2$ supported); the 'ease of use' variable was found to be a good fit for the third stepwise regression model (Adjusted $\mathrm{R}$ square $=0.534$ and ANOVA results $\mathrm{F}=149.567, \mathrm{p}<0.001$ ) and with $53.4 \%$ of the variance, an increase of $1.4 \%$ over the second model, it is significant in predicting behavior intention (H2 supported); and the 'localization' variable was found to be a good fit for the fourth stepwise regression model (Adjusted R square = 0.541 and ANOVA results $F=115.605, \mathrm{p}<0.001$ ) and with $54.1 \%$ of the variance, an increase of $0.7 \%$ over the third model, it is significant in predicting behavior intention (H8 supported).

The variables of 'usefulness', 'compatibility', 'mobility' and 'personalization' were found not to be significant in predicting behavior intention. In other words, $\mathrm{H} 4, \mathrm{H} 5, \mathrm{H} 6$ and $\mathrm{H} 7$ are rejected.

Table 1. ANOVA of stepwise regression models

\begin{tabular}{|c|c|c|c|c|c|c|}
\hline Model & & Sum of Squares & $\mathrm{df}$ & Mean Square & $\mathrm{F}$ & Sig. \\
\hline \multirow[t]{3}{*}{1} & Regression & 248.636 & 1 & 248.636 & 354.574 & $.000^{\mathrm{b}}$ \\
\hline & Residual & 272.075 & 388 & .701 & & \\
\hline & Total & 520.711 & 389 & & & \\
\hline \multirow[t]{3}{*}{2} & Regression & 272.265 & 2 & 136.132 & 212.051 & $.000^{\mathrm{c}}$ \\
\hline & Residual & 248.446 & 387 & .642 & & \\
\hline & Total & 520.711 & 389 & & & \\
\hline \multirow[t]{3}{*}{3} & Regression & 279.913 & 3 & 93.304 & 149.567 & $.000^{\mathrm{d}}$ \\
\hline & Residual & 240.798 & 386 & .624 & & \\
\hline & Total & 520.711 & 389 & & & \\
\hline \multirow[t]{3}{*}{4} & Regression & 284.141 & 4 & 71.035 & 115.605 & $.000^{\mathrm{e}}$ \\
\hline & Residual & 236.570 & 385 & .614 & & \\
\hline & Total & 520.711 & 389 & & & \\
\hline
\end{tabular}

a. Dependent Variable: Behavioral intention;

b. Predictors: (Constant), Attitude;

c. Predictors: (Constant), Attitude, Subjective norm;

d. Predictors: (Constant), Attitude, Subjective norm, Perceived ease of use;

e. Predictors: (Constant), Attitude, Subjective norm, Perceived ease of use, Localization.

Table 2. Stepwise regression model summary

\begin{tabular}{lllllll}
\hline Model & R & R Square & Adjusted R Square & $\begin{array}{l}\text { Std. Error } \\
\text { Estimate }\end{array}$ & $\begin{array}{c}\text { of } \\
\text { theChange Statistics } \\
\text { R Square Change }\end{array}$ & F Change \\
\hline 1 & .691 & .477 & .476 & .83739 & .477 & 354.574 \\
2 & .723 & .523 & .520 & .80124 & .045 & 36.806 \\
3 & .733 & .538 & .534 & .78983 & .015 & 12.260 \\
4 & .739 & .546 & .541 & .78388 & .008 & 6.881 \\
\hline
\end{tabular}


Table 3. Coefficients of stepwise regression models

\begin{tabular}{|c|c|c|c|c|c|c|}
\hline \multirow[b]{2}{*}{ Mode } & & \multicolumn{2}{|c|}{ Unstandardized Coefficients } & \multicolumn{2}{|c|}{$\begin{array}{l}\text { Standardized } \\
\text { Coefficients }\end{array}$} & \multirow[b]{2}{*}{ Sig. } \\
\hline & & $\mathrm{B}$ & Std. Error & Beta & $\mathrm{t}$ & \\
\hline \multirow[t]{2}{*}{1} & (Constant) & 1.021 & .217 & & 4.695 & .000 \\
\hline & Attitude & .834 & .044 & .691 & 18.830 & .000 \\
\hline \multirow[t]{3}{*}{2} & (Constant) & .796 & .211 & & 3.766 & .000 \\
\hline & Attitude & .660 & .051 & .547 & 12.927 & .000 \\
\hline & Subjective norm & .248 & .041 & .257 & 6.067 & .000 \\
\hline \multirow[t]{4}{*}{3} & (Constant) & .501 & .225 & & 2.228 & .026 \\
\hline & Attitude & .529 & .063 & .438 & 8.419 & .000 \\
\hline & Subjective norm & .240 & .040 & .249 & 5.948 & .000 \\
\hline & Perceived ease of use & .187 & .053 & .166 & 3.501 & .001 \\
\hline \multirow[t]{5}{*}{4} & (Constant) & -.008 & .295 & & -.025 & .980 \\
\hline & Attitude & .491 & .064 & .407 & 7.672 & .000 \\
\hline & Subjective norm & .253 & .040 & .261 & 6.257 & .000 \\
\hline & Perceived ease of use & .153 & .055 & .136 & 2.803 & .005 \\
\hline & Localization & .200 & .076 & .104 & 2.623 & .009 \\
\hline
\end{tabular}

a. Dependent Variable: Behavioral intention.

\section{Discussion}

The behavior intention of users of mobile commerce services in Hong Kong are mainly influenced by four factors: the attitude of the user toward mobile commerce services; the subjective norm (the intensity of social or peer group pressure to use mobile commerce services as perceived by users); the perceived ease of use of the mobile commerce services; and the localization of mobile commerce services.

\subsection{Implications}

Promoting mobile commerce services is expensive, and so to stay competitive it is crucial for marketers of mobile commerce service companies to promote their service in the most cost-effective way to make the best use of their promotional budget. To achieve optimum results, it is important for marketers and management to understand the relative importance of various key factors that might affect the behavior intention of mobile phone users. Better understanding of the mobile phone users allows the incumbents to direct their resources to deliver what customers value most. This, in turn, will ensure the incumbents to leverage the most from their investment.

Many researchers have ignored the attitude construct in their studies (Davis, 1989; Davis, Bagozzi, \& Warshaw, 1989; Venkatesh \& Davis, 2000) as it was argued that attitude has a minor impact on behavior intention in most contexts. However, this study found that attitude of the user toward mobile commerce services is the most influential factor affecting the user's intention to use mobile commerce services. The implication of the study is that mobile commerce service marketers should focus their time and effort on changing the attitude of prospective mobile commerce service users, for example by using advertisements to create a positive attitude toward mobile commerce services.

As a user's subjective norm is also found to have significant influence on the user's intention to use mobile commerce services, it is important for the management of mobile commerce service firms to make good use of peer pressure to promote their product. Marketers could focus their promotion on creating positive peer group opinions, e.g. advertisement on online mobile commerce service forums and discussion groups. Word of mouth behavior is extremely important in service industries and positive word of mouth behavior can be a useful and effective promotional tool (Mak, Wong, \& Tong, 2011). Marketers should also find ways to satisfy their existing customers so that they are willing to give positive word of mouth for their service and create positive peer pressure to prospective mobile commerce service users. Customer loyalty programs can also be used to create peer group pressure.

Perceived ease of use is another important factor. Management of mobile commerce service firms should ensure that their software development personnel are creating an easy-to-use interface instead of spending resources on creating technically elegant but difficult to use programs. Localization is also found to be important for behavior intention of mobile commerce users, a finding that highlights the importance of 'click and brick' in the digital 
world. This means that management of mobile commerce service firms should find ways to combine the use of the Internet (click) and the physical world (brick) through marketing and sales channels. In the retail sector this would include the use of online stores and physical stores to provide all-round coverage for their service.

\subsection{Limitations and Future Research}

While this research provides a better understanding of the relative importance of factors leading to the behavior intention of mobile commerce users in Hong Kong, it has limitations. One of the limitations is that the quantitative and cross-sectional nature of the study means that it only captured and analyzed a snapshot of the influence of various factors on behavior intention; a mix method longitudinal study would provide a more comprehensive picture over time. Another limitation is that, even though the study's sample size and response rate are high, the respondents were exclusively from the database of an executive development centre, which may not be truly representative of Hong Kong society. Finally, as the findings indicate that perceived usefulness, compatibility, mobility and personalization are not significantly predictive of behavior intention, further research needs to be conducted to determine why those factors do not influence behavior intention of mobile commerce service users in Hong Kong.

\section{References}

Ajzen, I. (1991). The theory of planned behavior. Organizational Behavior and Human Decision Processes, 50(2), 179-211. http://dx.doi.org/10.1016/0749-5978(91)90020-T

Ajzen, I., \& Fishbein, M. (1980). Understanding attitudes and predicting social behavior. Englewood Cliffs, NJ: Prentice-Hall.

Arpaci, I., Yardimci, Y., Özkan, S., \& Türetken, Ö. (2012). Organizational adoption of mobile communication technologies. European, Mediterranean \& Middle Eastern Conference on Information Systems. Munich, $\begin{array}{lllll}\text { Germany. } & \text { Retrieved } & \text { 2nd } & \text { December } & \text { from }\end{array}$ http://www.iseing.org/emcis/emcis2012/EMCISWebsite/proceedings/146.pdf

Chen, L., Gillenson, M. L., \& Sherrell, D. L. (2002). Enticing online consumers: An extended technology $\begin{array}{llll}\text { acceptance perspective. Information \& } & \text { Management, } & 39(8), & \text { 705-719. }\end{array}$ http://dx.doi.org/10.1016/S0378-7206(01)00127-6

Cherian, S. S., \& Rudrapatna, A. N. (2013). LTE location technologies and delivery solutions. Bell Labs Technical Journal, 18, 175-194. http://dx.doi.org/10.1002/bltj.21612

Chiang, I. P., \& Liao, Y. S. (2012). Exploring the key success factors of mobile commerce in Taiwan. 26th International Conference on Advanced Information Networking and Applications Workshops, 369-374. http://dx.doi.org/10.1109/WAINA.2012.76.

Davis, F. D. (1989). Perceived usefulness, perceived ease of use, and user acceptance of information technology. MIS Quarterly, 13(3), 319-340. http://dx.doi.org/10.2307/249008

Davis, F. D., Bagozzi, R. P., \& Warshaw, P. R. (1989). User acceptance of computer technology: A comparison of two theoretical models. Management Science, 35(8), 982-1003. http://dx.doi.org/ 10.1287/mnsc.35.8.982

Dholakia, R. R., \& Dholakia, N. (2004). Mobility and markets: emerging outlines of m-commerce. Journal of Business Research, 57(12), 1391-1396. http://dx.doi.org/10.1016/S0148-2963(02)00427-7

Fishbein, M., \& Ajzen, I. (1975). Belief, attitude, intention, and behavior: An introduction to theory and research. Reading, MA: Addison-Wesley.

Gao, L., \& Bai, X. (2014). A unified perspective on the factors influencing consumer acceptance of the Internet and of things technology. Asia Pacific Journal of Marketing and Logistics, 26(2), 211-231. http://dx.doi.org/10.1108/APJML-06-2013-0061

Herndon, N. C. (2013). A Retrospective/Perspective/Prospective Look at Marketing Channels. Journal of Marketing Channels, 20(3/4), 185-190. http://dx.doi.org/10.1080/1046669X.2013.803422

ITU. (2011). The World in 2011: ICT facts and figures. International Telecommunication Union.

Khalifa, M., \& Shen, K. N. (2008). Explaining the adoption of transactional B2C mobile commerce. Journal of Enterprise Information Management, 21(2), 110-124. http://dx.doi.org/10.1108/17410390810851372

Ko, E., Kim, E. Y., \& Lee, E. K. (2009). Modeling consumer adoption of mobile shopping for fashion products in Korea. Psychology and Marketing, 26(7), 669-687. http://dx.doi.org/10.1002/mar.20294

Langley, D. J., Bijmolt, T. H. A., Ortt, J. R., \& Pals, N. (2012). Determinants of Social Contagion during New 
Product Adoption. Journal of Product Innovation Management, 29, 623-638. http://dx.doi.org/10.1111/j.1540-5885.2012.00929.x

Li, C. Y. (2013). Persuasive messages on information system acceptance: A theoretical extension of elaboration likelihood model and social influence theory. Computers in Human Behavior, 29, $264-275$. http://dx.doi.org/10.1016/j.chb.2012.09.003

Lu, H. P., \& Su, Y. J. P. (2009). Factors affecting purchase intention on mobile shopping web sites. Internet Research, 19(4), 442-458. http://dx.doi.org/10.1108/10662240910981399

OFTA. (2012). Key telecommunications statistics. The Office of the Telecommunications Authority, HKSAR Government. Retrieved 30th November 2014 from http:/www.ofta.gov.hk/en/datastat/key_stat.html

Pan, W. T. (2014). Using data mining for service satisfaction performance analysis for mainland tourists in Taiwan. International Journal of Technology Management, 64(1), 31-44, http://dx.doi.org/10.1504/IJTM.2014.059236

Park, J. H. (2014). The effects of personalization on user continuance in social networking sites. Information Processing \& Management, 50(3), 462-475. http://dx.doi.org/10.1016/j.ipm.2014.02.002

Peña, J., \& Brody, N. (2014). Intentions to hide and unfriend Facebook connections based on perceptions of sender attractiveness and status updates. Computers in Human Behavior, 31(2), 143-150, http://dx.doi.org/10.1016/j.chb.2013.10.004

Tong, C., Wong, S. K. S., \& Lui, K. P. H. (2012). The influences of service personalization, customer satisfaction and switching costs on e-Loyalty. International Journal of Economics and Finance, 4(3), 105-114. http://dx.doi.org/10.5539/ijef.v4n3p105

Tsai, J. (2009). Shopping on the go: why mobile shopping -"M-Commerce" is finally getting a move on. CRM Magazine, 13(5), 19-20.

Tsai, J. P., \& Ho, C. F. (2013). Does design matter? Affordance perspective on smartphone usage. Industrial Management \& Data Systems, 113(9), 1248-1269. http://dx.doi.org/10.1108/IMDS-04-2013-0168

Wu, J. H., \& Wang, S. C. (2005). What drives mobile commerce? An empirical evaluation of the revised technology acceptance model. Information \& Management, 42(5), 719-729. http://dx.doi.org/10.1016/j.im.2004.07.001

Zhang, L., Nyheim, P., \& Mattila, A. S. (2014). The effect of power and gender on technology acceptance. Journal of Hospitality and Tourism Technology, 5(3), $299-314$. http://dx.doi.org/10.1108/JHTT-03-2014-0008

\section{Copyrights}

Copyright for this article is retained by the author(s), with first publication rights granted to the journal.

This is an open-access article distributed under the terms and conditions of the Creative Commons Attribution license (http://creativecommons.org/licenses/by/3.0/). 